\title{
Differences in the nocturnal flight activity of insect pests and beneficial predatory insects recorded by light traps: Possible use of a beneficial-friendly trapping strategy for controlling insect pests
}

\author{
GANG MA and Chun-SEN MA \\ Institute of Plant Protection, Chinese Academy of Agricultural Sciences, Yuanmingyuan West Road 2, Haidian District, \\ Beijing 100193, P.R. China; e-mail: csma@ippcaas.cn
}

Key words. Coleoptera, Lepidoptera, Coccinellidae, Chrysopidae, light trap, phototaxis

\begin{abstract}
The use of light traps for controlling insect pests is restricted since they kill both pests and beneficial insects. It may be a possible to reduce the numbers of beneficial insects trapped by adjusting nightly trapping time based on differences recorded in the timing of the nocturnal flight peaks of target pests and beneficials. To test this, insects were collected hourly over night using black light traps at three locations in China from 2003 to 2005. Groups of lepidopteran and coleopteran pests were selected as the target pests that we would control by trapping and groups of beneficial predatory insects the catches of which needed to be reduced. The highest numbers of Coleoptera were caught between 20:00 and 22:00 $\mathrm{h}$ and of most Lepidoptera between 02:00 and 04:00 h. The hourly numbers of predatory insects caught by light traps were evenly distributed throughout the night. A model was developed to describe the relationships between the cumulative proportions of insects caught and time of night. The model accurately describes the flight activity of insects that were mainly caught before midnight, after midnight and evenly throughout a night by using different parameters for the three different insect groups. A beneficial-friendly trapping strategy was developed to reduce the numbers of beneficial insects trapped, which was based on differences in the nocturnal flight activity of pests and beneficial insects and validated by a field study in Shandong province. Results show that this trapping strategy reduced the number of beneficial insects caught by $46 \%$ and the electricity consumption by $50 \%$ compared to the traditional strategy. Thus this strategy is more beneficial-friendly than the traditional trapping strategy for controlling pests.
\end{abstract}

\section{INTRODUCTION}

It is traditional in Integrated Pest Management to control insect pests by exploiting their phototactic responses. In early times (1st century B.C. -4 th century A.D), Roman beekeepers used light traps to control the moth Galleria mellonella (Steiner, 1991). There are a variety of light traps that are designed to sample, monitor and/or control vector mosquitoes (Reinert, 1989; Zhong et al., 2003), stored insect pests (Reed et al., 1934; Soderstrom, 1970), forest moths (Thomas \& Thomas, 1994; Brehm \& Axmacher, 2006) and various agricultural insect pests (Srivastava et al., 1992).

In recent years, as a non-chemical method for insect pest control, light traps have been widely used to control agricultural pests in developing countries such as China (Ma et al., 2009), India (Srivastava et al., 1992) and Brazil (Oliveira et al., 2008). In China, currently commercial light traps are being used by the Chinese Ministry of Agriculture to control agricultural pests over an area of more than 32 millions ha in 30 provinces. However, the detailed effects of light trapping on agro-ecosystems and biodiversity are unknown. Large numbers of non-target species, especially beneficial insects that play a significant role in pest control, are killed by light traps (Ma et al., 2005, 2009). It is proposed to use light trapping more widely in China (Zhang et al., 2004) and other countries (Upadhyay et al., 2000). Therefore, how to protect benefi- cial insects when controlling insect pests using light traps becomes an important issue.

It seems unavoidable that beneficial insects will be caught by light traps because various beneficial species are attracted to light traps (Nabli et al., 1999). However, the flight activity of different groups of insects recorded during the night using light traps differ (Ma et al., 2005). Therefore, by determining the times of the nocturnal flight peaks of target pests and beneficial insects it may be possible to reduce the catch of beneficials by operating the light traps mainly only when most of the pests are flying.

However, published correlative studies mainly focus on the sex ratio of some moth species and an ant species caught at different times (Persson, 1976; Kannowski, 1991; Ramakrishnan \& Venugopal, 1992) and the effects of ambient factors e.g. temperature, wind speed, wind direction, rainfall and phases of the moon on the response of insects to light traps (Charlton et al., 1999; Douthwaite, 1978; Kravtchenko, 1992; Steinbauer, 2003). Although the hourly distributions of species of Lepidoptera in light trap catches are recorded, the number of individuals collected and nightly samples of most species are small and have not been compared with that of other insect groups (Nowinszky et al., 2007). There are no detailed studies on the differences in the nocturnal flight activity of important pests and major beneficials (Ma et al., 2009). 
TABLE 1. Locations, main crops, dates and number of nights for which traps were operated at the different locations.

\begin{tabular}{|c|c|c|c|c|c|}
\hline \multirow{2}{*}{ Location } & \multirow{2}{*}{ Main crops } & \multicolumn{3}{|c|}{ Dates } & \multirow{2}{*}{$\begin{array}{l}\text { Number } \\
\text { of nights }\end{array}$} \\
\hline & & 2003 & 2004 & 2005 & \\
\hline $\begin{array}{l}\text { Changping } \\
\left(40^{\circ} 13^{\prime} 48^{\prime \prime} \mathrm{N}, 116^{\circ} 09^{\prime} 32^{\prime \prime} \mathrm{E}\right)\end{array}$ & Soybean-Maize & July $22-28$ & July $27-$ Aug. 3 & June 6-25 & 27 \\
\hline $\begin{array}{l}\text { Haidian } \\
\left(39^{\circ} 57^{\prime} 50^{\prime \prime} \mathrm{N}, 116^{\circ} 19^{\prime} 37^{\prime \prime} \mathrm{E}\right)\end{array}$ & Wheat-Maize & - & $\begin{array}{c}\text { May } 27-\text { June } 1 \\
\text { July 6-12 } \\
\text { Sep. 6-12 }\end{array}$ & June 4-Aug. 3 & 69 \\
\hline $\begin{array}{l}\text { Zijiao } \\
\left(37^{\circ} 30^{\prime} 64^{\prime \prime} \mathrm{N}, 117^{\circ} 31^{\prime} 28^{\prime \prime} \mathrm{E}\right)\end{array}$ & Wheat-Cotton & July $20-30$ & July $25-30$ & - & 12 \\
\hline
\end{tabular}

Note: "-" means no samples.

The aim of this study was to determine the timing of the nocturnal flight activity of target pests and beneficial insects by recording hourly throughout the night the numbers of different insect species caught by light traps at three different locations from 2003 to 2005. Then use the results to develop a trapping strategy that would result in a reduction in the catch of beneficial insects by not running the light trap throughout the night. Finally, the new trapping strategy was validated by a field study in Shandong province.

\section{MATERIAL AND METHODS}

\section{Light traps and trapping strategies}

Commercial black light traps (PS-15, Jiaduo Ltd., China) were used as they are widely used for pest control in China. The trap mainly consists of a perspex roof, black light tube (15 Watt, wavelength $\approx 350 \mathrm{~nm}$ ), electrical wire net, funnel, collecting bag and power supply. Each trap was fitted with a microcomputer timer switch (KG316T, Zhuoyi Ltd., China) that automatically controlled the switch status to "on" or "off" at any time during a 24-h cycle. Trapping schedules adopted in this study include (1) traditional trapping schedule - light trap programmed to be "on" for $8 \mathrm{~h}$ from 20:00 to 04:00, and (2) beneficial-friendly trapping schedule - light trap programmed to be "on" for a total of $4 \mathrm{~h}$ from 20:00 to $22: 00$ and $02: 00$ to $04: 00$. The latter trapping schedule was originally discussed and proposed by Ma et al. (2009) and modified in this study. The bottom of each trap was positioned $1.8 \mathrm{~m}$ above the ground to ensure that the light was visible to nocturnal insects.

\section{Trapping, sampling and insect identification}

To determine the timing of the nocturnal flight activity of different insect species recorded by light traps, the traditional nightly trapping schedule was used to catch nocturnal insects at three different locations from 2003 to 2005. Sampling information for each location, including geographic coordinates, main crops, dates and number of nights for which traps were operated are given in Table 1. On all the nights the traps were operated, sundown and sunrise were between 18:28-19:33 and 04:50-05:53, respectively. The insect collecting bag suspended below each light trap was replaced by a new one every hour during the night and then frozen at $-18^{\circ} \mathrm{C}$ in a refrigerator for 30 min to kill the insects. Insect species and numbers were identified and counted in the laboratory. A total of 108 nights $\times 8$ samples/night $=864$ samples were collected.

To compare the effects of these two trapping schedules on the numbers of insects caught, a standard light trap and a timecontrolled light trap were sited near a winter wheat-transgenic BT (Bacillus thuringiensis) cotton field at Beiguo Farm $\left(37^{\circ} 30^{\prime} 64^{\prime \prime} \mathrm{N}, 117^{\circ} 31^{\prime} 28^{\prime \prime} \mathrm{E}\right)$, Zijiao, Shandong Province, and run continuously during the growing season from June till September in 2004. In order to eliminate the interaction between the two traps in terms of their attracting insects they were positioned about $200 \mathrm{~m}$ apart. Nightly catches of insects by the two traps were identified and counted.

\section{Statistical analysis}

Lepidopteran and coleopteran pests and predatory insects are among the insects most frequently caught by light traps in central China (Ma et al., 2005). Therefore, lepidopteran and coleopteran pests were selected as the target pests that should be caught and predatory insects as those the catches of which needed to be reduced. For each of the three main insect groups, i.e. "lepidopteran pests", "coleopteran pests" and "predatory insects", catches of $\geq 5 /$ night over a period of at least 5 nights were used to determine the timing of nocturnal flight activity of these insects. When fewer than $\geq 5$ insects in each of these groups were caught each night, the percentages of the total catch of each of these groups of insects that were caught each hour (average $\pm \mathrm{SE}$ ) over the same period of time were also used to describe the nocturnal flight activity of each species.

The nocturnal flight activity of the three groups of insects were determined using the catches on nights when the total number of insects caught belonging to a particular group of insects was $\geq 15$. For coleopteran pests, lepidopteran pests and predatory insects, there were 57,55 and 34 nightly catches, respectively, that met the above criterion. The catches on these nights were used to determine the relationships between the cumulative proportions of insects trapped belong to the three groups at different hours during the course of the night starting at 20:00, e.g. 1, 2, . 7, $8 \mathrm{~h}$ using "Graph wizard" in SigmaPlot software (SPSS Inc., 2000). Then, the relationships for the three groups of insects were used to develop an integrated general model that describes the relationships. Parameters of the integrated model were estimated using original data and regression analysis using Systat 6.0.1 (SPSS Inc., 1996).

Numbers of individuals of the three insect groups trapped nightly using the two trapping strategies were used to compare the differences in the seasonal fluctuations in the numbers of both pests' and beneficials' caught by light traps operating the two strategies. For each insect group, the differences (\%) in the total numbers trapped using the traditional trapping strategy (treated as 100\%) and the beneficial-friendly trapping strategy were calculated to determine whether the latter strategy was the better for trapping pests and reducing the catches of beneficials.

\section{RESULTS}

In this study, the 102 most common insect species caught by the traps were identified including pests and beneficials. The pests were mainly Lepidoptera (3453 individuals belong to 55 species) and Coleoptera (11752 
Coleopteran pests

Coccinellid predators

(a)

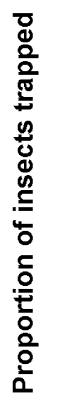

Lepidopteran pests

Chrysopid predators

(b)

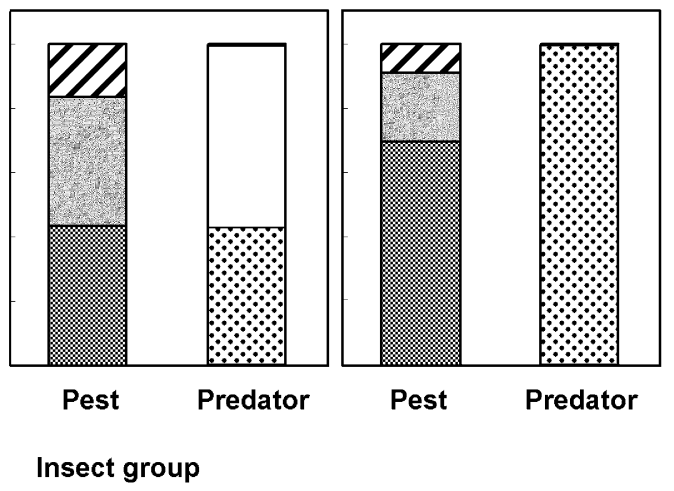

Fig. 1. The proportions of coleopteran, lepidopteran and other pests, and coccinellid, chrysopid and other predators in the total catches of pests and predators, respectively, caught by light traps at Changping (a), Haidian (b) and Zijiao (c). Data consists of the total numbers caught on 108 nights over the period 2003 to 2005 .

individuals belong to 22 species) and the beneficials principally predatory insects (1503 individuals belong to 6 species). Thus in the light trap catches, coleopteran and lepidopteran pests were the most abundant pests and predatory insects the most abundant natural enemies (Fig. 1).

\section{Nocturnal flight activity of pest and beneficial insects}

The 10 most abundant coleopteran pests and 12 most abundant lepidopteran pests in the light trap catches were selected as representatives of coleopteran and lepidopteran pests, respectively. Similarly, five predatory species i.e. two coccinellids and three chrysopids were the most abundant predatory insects in the catches and selected as the representatives of predatory insects. The percentage of the total catch of each species caught hourly between 20:00 and 04:00 $\mathrm{h}$ and other sampling information for these species is presented in Table 2.

Hourly percentages of all the species of Coleoptera trapped was greatest in the first two hours, ranging between $50 \sim 80 \%$, and then the percentage trapped each hour decreased dramatically after 22:00 (Table 2). In contrast, hourly percentages of most of the species of Lepi- doptera trapped was $<20 \%$ before $02: 00$ and then increased to $20-40 \%$ in the last two hours (02:00-04:00). For Macdunnoughia crassisigna and Hyphantria cunea, the peaks in the percentages trapped occurred between 01:00 and 03:00. Hourly percentages of predatory insects trapped remained relatively constant throughout the night (Table 2).

\section{Comparison of the nocturnal flight activity of pests and beneficial insects}

Relationships between the cumulative percentages $(P)$ of insects belonging to the three groups trapped after 20:00 h $(t)$ were determined using SigmaPlot 2000. The relationships for coleopteran and lepidopteran pests differ but are both nonlinear whereas that for predatory insects is linear. The integrated model

$$
P=P_{0}+a . t+b . e^{c . t}
$$

which includes a linear model and an exponential growth model, was developed to describe the above three relationships. In this model, parameter $P_{0}$ is a correction constant, $a, b$ and $c$ are parameters that determine the rate of increase in $P$ with $t$.
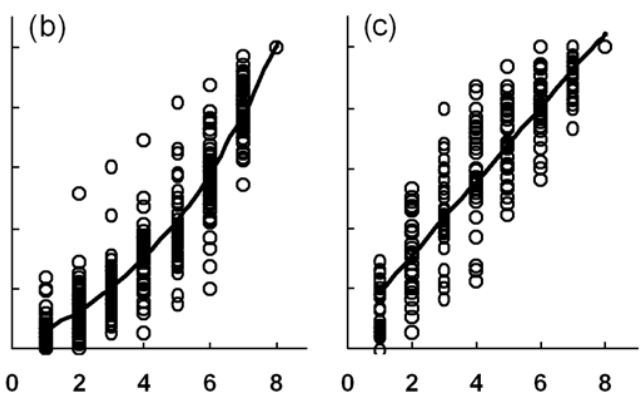

Hours after 20:00 (h)

Fig. 2. The relationships between the cumulative percentages of Coleoptera pests (a), Lepidoptera pests (b) and predatory insects (c) trapped and time in hours after 20:00. Lines and circles are the regression curves and hourly percentages, respectively. 
TABLE 2. The distribution in time during the night of the average percentage of the total catch (\%, average \pm SE) of each species caught each hour.

\begin{tabular}{|c|c|c|c|c|c|c|c|c|c|c|}
\hline \multirow[b]{2}{*}{ Species } & \multicolumn{8}{|c|}{ Time of night } & \multirow{2}{*}{$\begin{array}{c}\text { No. of } \\
\text { individuals } \\
\text { / nights }\end{array}$} & \multirow{2}{*}{$\begin{array}{c}\text { Sam- } \\
\text { pling } \\
\text { location }\end{array}$} \\
\hline & $20-21$ & $21-22$ & $22-23$ & $23-24$ & $00-01$ & $01-02$ & $02-03$ & $03-04$ & & \\
\hline \multicolumn{11}{|l|}{ Pest InSECts } \\
\hline \multicolumn{11}{|l|}{ Coleoptera } \\
\hline Anomala corpulenta & $42.5 \pm 3.2$ & $21.6 \pm 1.8$ & $12.2 \pm 1.4$ & $7.9 \pm 1.1$ & $5.9 \pm 1.1$ & $5.1 \pm 1.2$ & $3.4 \pm 0.7$ & $1.0 \pm 0.5$ & $1532 / 49$ & $\mathrm{C} / \mathrm{H} / \mathrm{Z}$ \\
\hline A. exoleta & $38.7 \pm 1.9$ & $13.8 \pm 3.0$ & $20.3 \pm 1.7$ & $9.0 \pm 3.8$ & $8.0 \pm 6.5$ & $9.8 \pm 3.1$ & $0.5 \pm 0.5$ & - & $129 / 6$ & $\mathrm{C} / \mathrm{Z}$ \\
\hline Holotrichia oblita & $50.8 \pm 5.1$ & $16.3 \pm 4.4$ & $12.4 \pm 4.2$ & $10.6 \pm 3.1$ & $5.4 \pm 2.7$ & $1.4 \pm 1.4$ & $3.2 \pm 1.6$ & - & $90 / 7$ & $\mathrm{C}$ \\
\hline H. parallela & $51.9 \pm 4.6$ & $18.4 \pm 3.5$ & $8.6 \pm 4.3$ & $8.1 \pm 5.2$ & $1.4 \pm 1.4$ & - & $7.5 \pm 3.4$ & $4.1 \pm 2.6$ & $47 / 6$ & Z \\
\hline Apogonia chinensis & $30.9 \pm 5.2$ & $19.5 \pm 4.5$ & $24.0 \pm 5.3$ & $9.1 \pm 2.5$ & $7.2 \pm 2.8$ & $5.5 \pm 2.2$ & $3.5 \pm 2.1$ & $0.4 \pm 0.4$ & $152 / 13$ & $\mathrm{C} / \mathrm{H}$ \\
\hline Metabolus tumidifrons & $44.0 \pm 5.8$ & $22.7 \pm 3.1$ & $12.2 \pm 2.1$ & $10.0 \pm 2.6$ & $4.6 \pm 3.0$ & $4.3 \pm 2.2$ & $1.5 \pm 1.0$ & $0.7 \pm 0.7$ & $157 / 11$ & $\mathrm{H}$ \\
\hline Serica orientalis & $44.9 \pm 4.1$ & $32.5 \pm 3.6$ & $13.4 \pm 3.0$ & $5.2 \pm 1.4$ & $1.0 \pm 0.6$ & $1.2 \pm 1.1$ & $1.1 \pm 0.9$ & - & $259 / 18$ & $\mathrm{H}$ \\
\hline Adoretus tenuimaculatus & $53.5 \pm 5.5$ & $23.5 \pm 4.4$ & $6.9 \pm 4.3$ & $1.5 \pm 1.5$ & $1.5 \pm 1.5$ & $4.0 \pm 4.0$ & $1.5 \pm 1.5$ & $7.5 \pm 3.7$ & $40 / 5$ & Z \\
\hline Melanotus caudex & $46.8 \pm 5.0$ & $32.6 \pm 5.6$ & $10.9 \pm 2.7$ & $3.9 \pm 1.8$ & $2.2 \pm 1.3$ & - & $1.2 \pm 1.1$ & $2.3 \pm 1.1$ & $285 / 10$ & $\mathrm{C} / \mathrm{H} / \mathrm{Z}$ \\
\hline \multicolumn{10}{|l|}{ Lepidoptera } & $\mathrm{C} / \mathrm{H}$ \\
\hline Mythimna separata & $5.2 \pm 1.4$ & $6.6 \pm 1.6$ & $6.0 \pm 1.1$ & $11.7 \pm 1.9$ & $12.6 \pm 2.5$ & $14.4 \pm 1.9$ & $22.9 \pm 3.2$ & $20.5 \pm 3.0$ & $452 / 32$ & $\mathrm{C} / \mathrm{H} / \mathrm{Z}$ \\
\hline Agrotis ypsilon & $2.7 \pm 0.8$ & $9.9 \pm 1.7$ & $10.5 \pm 1.6$ & $11.7 \pm 1.6$ & $11.5 \pm 1.8$ & $13.4 \pm 1.6$ & $20.0 \pm 2.0$ & $20.5 \pm 2.4$ & $487 / 47$ & $\mathrm{C} / \mathrm{H} / \mathrm{Z}$ \\
\hline A. segetum & $4.0 \pm 1.0$ & $5.4 \pm 1.3$ & $5.9 \pm 1.2$ & $9.3 \pm 2.0$ & $14.6 \pm 2.1$ & $19.2 \pm 3.6$ & $20.7 \pm 2.5$ & $21.0 \pm 2.8$ & $295 / 32$ & $\mathrm{C} / \mathrm{H}$ \\
\hline Mamestra brassicae & $5.3 \pm 1.9$ & $6.5 \pm 2.2$ & $9.0 \pm 2.1$ & $10.3 \pm 2.9$ & $9.6 \pm 3.0$ & $15.7 \pm 3.7$ & $22.0 \pm 4.0$ & $21.6 \pm 4.3$ & $138 / 16$ & $\mathrm{C} / \mathrm{H}$ \\
\hline Scotogramma trifolii & $6.8 \pm 1.6$ & $3.4 \pm 1.5$ & $2.8 \pm 1.5$ & $4.4 \pm 1.3$ & $3.2 \pm 1.1$ & $8.5 \pm 1.8$ & $32.1 \pm 4.0$ & $38.9 \pm 4.2$ & $277 / 32$ & $\mathrm{C} / \mathrm{H}$ \\
\hline Ostrinia furnacalis & $3.4 \pm 2.2$ & $4.3 \pm 1.3$ & $8.2 \pm 1.9$ & $9.4 \pm 2.2$ & $9.5 \pm 1.7$ & $9.7 \pm 2.4$ & $28.0 \pm 3.8$ & $27.8 \pm 4.6$ & $233 / 18$ & $\mathrm{C} / \mathrm{H}$ \\
\hline Macdunnoughia crassisigna & $2.2 \pm 2.2$ & $1.9 \pm 1.9$ & $4.4 \pm 2.9$ & $1.9 \pm 1.9$ & $11.3 \pm 4.7$ & $28.3 \pm 10.7$ & $31.2 \pm 8.5$ & $18.9 \pm 5.5$ & $83 / 9$ & $\mathrm{C}$ \\
\hline Spodoptera exigua & $5.5 \pm 3.5$ & $3.3 \pm 2.2$ & $4.8 \pm 3.1$ & $3.4 \pm 2.4$ & $14.5 \pm 2.5$ & $14.8 \pm 4.7$ & $25.9 \pm 3.3$ & $27.9 \pm 6.7$ & $67 / 6$ & $\mathrm{H}$ \\
\hline Semiothisa cinerearia & $4.4 \pm 2.9$ & $7.9 \pm 2.9$ & $5.3 \pm 2.5$ & $3.6 \pm 2.4$ & $9.7 \pm 2.6$ & $12.9 \pm 6.9$ & $29.6 \pm 5.1$ & $26.6 \pm 5.6$ & $54 / 7$ & $\mathrm{H}$ \\
\hline Ascotis selenaria & - & $4.9 \pm 3.3$ & $4.0 \pm 4.0$ & $7.8 \pm 3.8$ & $7.3 \pm 4.5$ & $9.1 \pm 5.5$ & $29.6 \pm 7.5$ & $37.4 \pm 4.9$ & $40 / 5$ & $\mathrm{Z}$ \\
\hline Hyphantria cunea & - & - & - & $6.2 \pm 3.8$ & $8.6 \pm 5.7$ & $39.5 \pm 14.1$ & $39.5 \pm 11.3$ & $6.2 \pm 3.8$ & $40 / 5$ & Z \\
\hline Cnaphalocrocis medinalis & $5.7 \pm 3.0$ & $4.3 \pm 2.2$ & $6.0 \pm 4.3$ & $5.1 \pm 3.2$ & $9.2 \pm 2.6$ & $11.1 \pm 5.6$ & $37.3 \pm 8.2$ & $21.3 \pm 7.2$ & $72 / 5$ & $\mathrm{H}$ \\
\hline \multicolumn{11}{|l|}{ Predatory insects } \\
\hline Chrysopidae spp. & $5.1 \pm 2.1$ & $12.9 \pm 2.5$ & $14.3 \pm 2.7$ & $15.3 \pm 2.9$ & $14.6 \pm 2.7$ & $11.4 \pm 2.3$ & $15.2 \pm 2.9$ & $11.2 \pm 2.5$ & $455 / 26$ & $\mathrm{C} / \mathrm{H}$ \\
\hline Harmonia axyridis & $19.6 \pm 1.8$ & $21.2 \pm 2.1$ & $15.1 \pm 1.9$ & $10.0 \pm 1.6$ & $9.8 \pm 1.5$ & $9.1 \pm 1.3$ & $8.7 \pm 1.8$ & $6.5 \pm 1.4$ & $343 / 31$ & $\mathrm{C} / \mathrm{H} / \mathrm{Z}$ \\
\hline Propylea japonica & $19.0 \pm 2.0$ & $19.5 \pm 2.3$ & $13.5 \pm 2.4$ & $13.5 \pm 3.1$ & $8.2 \pm 2.3$ & $7.9 \pm 2.6$ & $10.5 \pm 2.6$ & $7.8 \pm 2.5$ & $229 / 19$ & $\mathrm{C} / \mathrm{H} / \mathrm{Z}$ \\
\hline
\end{tabular}

Note: “-” means no trapped individual was appeared. C, H and Z represent Changping, Haidian and Zijiao, respectively. Chrysopidae spp., i.e. Chrysopa septempunctata, Chrysopa formosa and Chrysoperla sinica.

To describe the "nonlinear" curves of coleopteran and lepidopteran pests, parameter $a$ was set to 0 and for describing the "linear" curve of predatory insects, parameters $b$ and $c$ were set to 0 . Model parameters, estimate accuracy $\left(R^{2}\right)$ and significance test $\left(P_{0.001}\right)$ are presented in Table 3. The regression curves of the relationships between $P$ and $t$ are depicted in Fig. 2 .

TABLE 3. Parameters of the regression models used to describe the nocturnal flight activity of the three insect groups recorded using light traps. ${ }^{* * *}$ significant at $P=0.001$.

\begin{tabular}{lcccccc}
\hline \multirow{2}{*}{ Insect group } & \multicolumn{7}{c}{ Model parameter } & \multirow{2}{*}{$R^{2}$} & $P$ \\
\cline { 2 - 5 } & $P_{0}$ & $a$ & $b$ & $c$ & & \\
\hline Coleopteran pests & 100.3 & 0 & -87.8 & -0.403 & 0.785 & $* * *$ \\
Lepidopteran pests & -18.4 & 0 & 19.6 & 0.226 & 0.920 & $* * *$ \\
Predatory insects & 6.5 & 12.2 & 0 & 0 & 0.859 & $* * *$ \\
\hline
\end{tabular}

\section{Effect of different trapping strategies on the numbers of pests and beneficials caught by light traps}

Seasonal changes in the numbers of each of the three insect groups caught by light traps operated using the traditional and beneficial-friendly strategies were similar (Fig. 3), indicating that the different trapping strategies did not affect the seasonal fluctuations in the numbers trapped. The total numbers of coleopteran and lepidopteran pests trapped using the beneficial-friendly trapping strategy were 28.9 and $24.5 \%$ less, respectively, than those caught using the traditional trapping strategy. However, by using the beneficial-friendly trapping strategy $46 \%$ fewer predatory insects were caught (Fig. 4).

\section{DISCUSSION}

In this study, we collected a large quantity of field data on the behavioural response of nocturnal insects to light traps and analyzed their flight activity. First, the flight activity of three groups of insects studied differed. The 


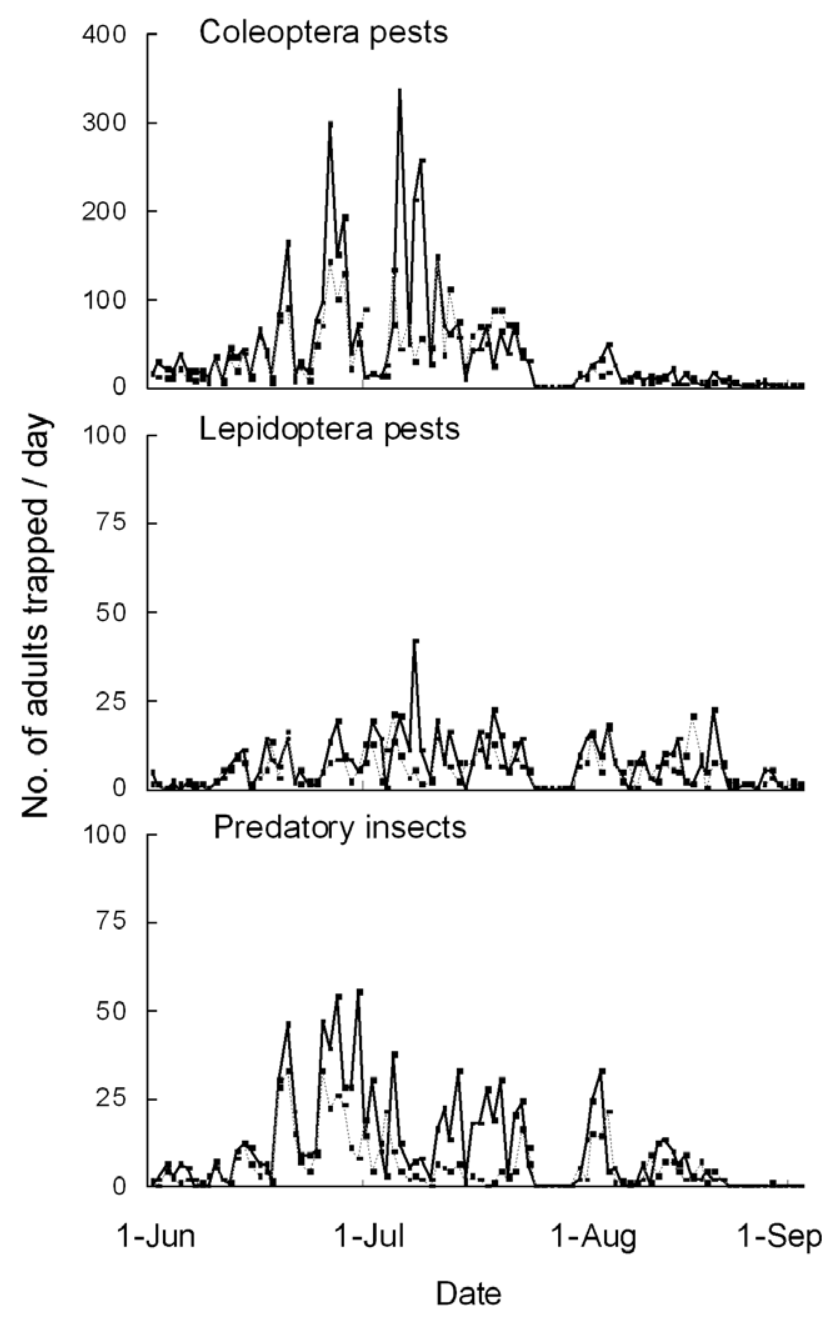

Fig. 3. The trends in the numbers of insects belonging to the different groups caught each day during 2004 using a traditional trapping strategy (solid lines) and beneficial-friendly trapping strategy (dashed lines) at Beiguo farm, Shandong.

largest catches of most coleopteran pests were between 20:00 and 22:00 h, and very few caught after midnight (Table 2). Our results are in line with a previous study that shows that the scarabaeid pests, Polyphylla gracilicornis, Holotrichia oblita, Holotrichia titanis and Anomala exoleta are all mainly caught (over $80 \%$ ) before 24:00 h (Ma et al., 2005). Conversely, the catches of lepidopteran pests were largest between midnight and dawn (Table 2). In addition, the catches of more than 20 other common lepidopteran pests also increased after midnight. This accords with the fact that other moth pests, e.g., armyworm, Spodoptera exempta (Douthwaite, 1978), autumn gum moth, Mnesampela privata (Steinbauer, 2003) and 8 other species of Noctuidae (Kuniyasu \& Midori, 1958) are mainly caught by light traps after 01:00 $\mathrm{h}$. There is no obvious peak in the nocturnal flight activity of the predatory insects studied (Table 2), which conforms with that reported for other species of predatory insects i.e. the green lacewing Chrysopa formosa (Ma et al., 2005) and several species of tiger beetle, Cicindela spp. (Liu, 1982). Second, the nocturnal flight activities of the different species included in each of the three groups,

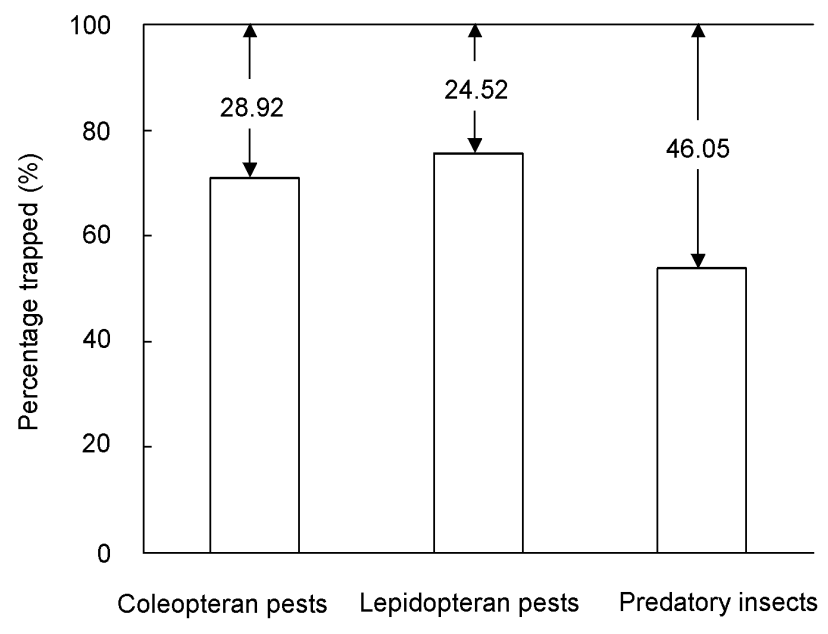

Fig. 4. The differences, expressed in terms of percentage (number above each column), in the total number of coleopteran and lepidopteran pests and predatory insects caught by light traps operated using the traditional trapping strategy (horizontal line i.e. $100 \%$ ) and a beneficial-friendly trapping strategy (open bars). Data were collected Jun.-Sep. 2004 at Beiguo farm, Shandong province.

coleopteran pests, lepidopteran pests and predatory insects, are similar. A model describing the three different patterns of nocturnal flight activity recorded was developed by integrating the relationships between cumulative percentages of insects belonging to the three groups caught by the light traps and time of night. This model clearly indicates that nocturnal flight activity of the three groups of insects studied differ with most of the insects in one group caught before midnight, in another after midnight and the other evenly throughout the night (Fig. 2 and Table 3). Based on this analysis, the three patterns in nocturnal flight activity are designated: "Before-midnight", "After-midnight" and "Whole-night", as it is highly likely that each pattern is characteristic of all the species in a particular group of insects.

The nocturnal flight activity of insects has been recorded for a long time using light traps but temporal differences in the flight activity of pest and beneficial insects are not well documented. Theoretically temporal differences in their flight activity could be used to develop light trapping strategies that would result in fewer beneficial insects being caught. The results presented indicate that there are significant differences in their temporal flight activity (Fig. 2 and Table 3). Based on these differences, we developed a beneficial-friendly strategy for trapping pest insects and reducing the numbers of beneficial insects captured by light traps operated in a cotton field (Figs 3 and 4). The field results indicate that by not running light traps all night but only for particular periods of time during the night it is possible to reduce the consumption of electricity and the numbers of beneficial insects caught (approximately by $50 \%$ ) by the traps. This beneficial-friendly trapping strategy complies with the government policy of saving energy and preserving biodiversity and also the growers' economic interest in reducing the cost of running the traps. Further- 
more, pests which have no or a weak phototactic response, such as aphids, thrips and mites might be better controlled by reducing catches of beneficial insects. Potentially non-target and other beneficial insects, which play an important role in agricultural ecosystem balance, will also be preserved. Therefore, the beneficial-friendly trapping strategy is a good way of reducing the numbers of beneficial insects caught when using light traps for controlling insect pests.

The pests and beneficial insects studied are of agricultural importance in most regions of China. Both the larvae and adults of the coleopteran pests are serious pests of many crops and are even destructive in many orchards and gardens (Shu et al., 2007). The larvae of the lepidopteran pests are also serious pests of various crop plants. Some of them are notorious pests worldwide. In China, $H$. axyridis and $P$. japonica, the two predatory lady beetles studied, are the most important insect predators of pest insects because they are widely distributed and attack a wide range of prey (Koch, 2003; Du et al., 2004). The species of green lacewings studied are popular in central China and play a significant role in pest control in natural ecosystems. Therefore, as the use of the beneficialfriendly trapping strategy results in a reduction in the numbers of beneficial insects caught by light traps it should be more widely used in many regions of China and other countries.

In addition to the three patterns of nocturnal flight activity described there might be other patterns. The nocturnal flight activity of adults of the cotton bollworm, Helicoverpa armigera, is bimodal with the first peak in activity at 20:00-22:00 $\mathrm{h}$ and the second at 02:00-04:00 $\mathrm{h}$ (unpubl. data) rather than the "After-midnight" pattern of most Lepidoptera. A similar bimodal pattern is also reported in other studies (Kravtchenko, 1992; Ma et al., 2009). The nocturnal flight activity of adults of the yellow stem borer, Chilo suppressalis, is also bimodal with a large peak during 21:00 to $22: 00 \mathrm{~h}$ and a small peak after midnight (Ramakrishnan \& Venugopal, 1992). Therefore, further detailed studies are needed determine the patterns in the nocturnal flight activity of other species of pests and beneficial insects. This will facilitate the development of more comprehensive trapping strategies by adjusting when during a night a light trap is operational with the objective of optimizing the conflicting requirements of using these traps for controlling pest insects and the need to reduce the numbers of beneficial insects caught by these traps in various agricultural ecosystems.

ACKNOWLEDGEMENTS. The authors acknowledge the help of X. Chang, H. Yang and J. Tian with collecting samples. We also thank W. Li for constructive comments on this paper. This research was partly financially supported by research grant (201103024) from the Ministry of Agriculture (MOA), PR China.

\section{REFERENCES}

Brehm G. \& AXMACher J.C. 2006: A comparison of manual and automatic moth sampling methods (Lepidoptera: Arctiidae,
Geometridae) in a rain forest in Costa Rica. Environ. Entomol. 35: 757-764.

Charlton R.E., Carde R.T. \& Wallner W.E. 1999: Synchronous crepuscular flight of female Asian gypsy moths: relationships of light intensity and ambient and body temperatures. J. Insect Behav. 12: 517-531.

Douthwaite R.J. 1978: Some effects of weather and moonlight on light-trap catches of the armyworm, Spodoptera exempta (Walker) (Lepidoptera: Noctuidae), at Muguga, Kenya. Bull. Entomol. Res. 68: 533-542.

Du L., Ge F., Zhu S. \& Parajulee M.N. 2004: Effect of cotton cultivar on development and reproduction of Aphis gossypii (Homoptera: Aphididae) and its predator Propylea japonica (Coleoptera: Coccinellidae). J. Econ. Entomol. 97: $1278-1283$.

KanNowski P.B. 1991: Occurrence of alates of the Neotropical ant, Paraponera clavata (Hymenoptera, Formicidae) at lights during the dry-wet seasons interface in Panama. J. Entomol. Sci. 26: 375-377.

Koch R.L. 2003: The multicolored Asian lady beetle, Harmonia axyridis: A review of its biology, uses in biological control, and non-target impacts. J. Insect Sci. 3: 1-16.

KRAVTCHENKo V. 1992: Imago activity rhythms of some pest species of Noctuidae in Ethiopia (Insecta: Lepidoptera). Trop. Pest Manag. 38: 75-76.

KunIYASU M. \& Midori U. 1958: An observation on the seasonal and hourly variation of insects gathering to a light trap. Jap. J. Entomol. 26: 163-167 [in Japanese, English abstr.].

Liu L.C. 1982: A prieliminary study of insects response to light source. J. Nanjing Agr. Univ. 2: 52-59 [in Chinese, English abstr.].

Ma C.S., Ma G., Chang X.Q., Liu X.Y., Hu C.L. \& Yang H.P. 2005: Daily rhythm of phototaxis of chafers and natural enemies of insects in Beijing. In Yang H.W. (ed.): Progress in Biocontrol at the Beginning of the 21st Century in China. Chinese Agricultural Science and Technology Press, Beijing, pp. 171-172 [in Chinese, English abstr.].

Ma C.S., Ma G., Chang X.Q. \& Yang H.P. 2009: Environmentfriendly methods for controlling cotton bollworm moths, Helicoverpa armigera. Chin. J. Environ. Entomol. 31: 220-226 [in Chinese, English abstr.].

Nabli H., Bailey W. \& NeCiBI S. 1999: Beneficial insect attraction to light traps with different wavelengths. Biol. Contr. 16: $185-188$.

Nowinszky L., Meszaros Z. \& Puskas J. 2007: The hourly distribution of moth species caught by a light trap. Appl. Ecol. Environ. Res. 5: 103-107.

Oliveira A.C., Veloso V.R., Barros R.G., Fernandes P.M. \& SouzA E.R. 2008: Capture of Tuta absoluta (Meyrick) (Lepidoptera: Gelechiidae) with light trap in tomato crop. Pesq. Agropec. Trop. 38: 153-157 [in Portuguese, English abstr.].

Persson B. 1976: Influence of weather and nocturnal illumination on the activity and abundance of population of noctuids (Lepidoptera) in south costal Queensland. Bull. Entomol. Res. 66: 33-63.

RAMAKRISHNAN S. \& VenUgOPAL M.S. 1992: Hourly catches of yellow stem borer (YSB). Int. Rice Res. Newsl. 17: 21.

Reed W.D., Morrill J.R. \& Livingstone E.M. 1934: Experiments with suction light traps for combating the cigarette beetle. J. Econ. Entomol. 27: 796-801.

REINERT W.C. 1989: The New Jersey light trap: an old standard for most mosquito control programs. In: Proceedings of the Seventy-Sixth Annual Meeting of the New Jersey Mosquito Control Association. Atlantic County Mosquito Unit, pp. 17-25. 
Shu C., Liu R., Wang R., Zhang J., Feng S., Huang D. \& Song F. 2007: Improving toxicity of Bacillus thuringiensis strain contains the cry8Ca gene specific to Anomala corpulenta larvae. Curr. Microbiol. 55: 492-496.

Soderstrom E.L. 1970: Effectiveness of green electroluminescent lamps for attracting stored-product insects. J. Econ. Entomol. 63: 726-731.

Srivastava V.K., Diwakar M.C. \& Pawar A.D. 1992: Light trap and rice pests management. Plant Prot. Bull. (Faridabad) 44: 39-41.

SteinBaUer M.J. 2003: Using ultra-violet light traps to monitor autumn gum moth, Mnesampela private (Lepidoptera: Geometridae), in south-eastern Australia. Austal. Forest. 66: 279-286.

SteINER A. 1991: The use of light-traps for pest control in Roman times. 1st century B.C.-4th century A.D. (Insecta, Lepidoptera, Pyralidae). Beitr. Entomol. 41: 405-409.
Thомаs A.W. \& Thомаs G.M. 1994: Sampling strategies for estimating moth species diversity using a light trap in a northeastern softwood forest. J. Lepid. Soc. 48: 85-105.

Upadhyay R.N., Dubey O.P. \& Vaishampayan S.M. 2000: Studies on the common predatory and parasitic species of insects collected on light trap. JNKVV Res. J. 33: 50-57.

Zhong H., Yan Z.C., Jones F. \& Brock C. 2003: Ecological analysis of mosquito light trap collections from west central Florida. Environ. Entomol. 32: 807-815.

Zhang G.X., Zheng G., Li X.J. \& BU J. 2004: Discussion of using frequency trembler grid lamps from angle of protecting biodiversity. Chin. Bull. Entomol. 41: 532-535 [in Chinese, English abstr.].

Received October 12, 2011; revised and accepted January 4, 2012 